\section{National HIV Testing Day - June 27, 2017}

National HIV Testing Day, June 27, highlights the importance of testing in detecting, treating, and preventing human immunodeficiency virus (HIV) infection. Awareness of HIV infection through HIV testing is the first step to prevention, health care, and social services that improve quality of life and length of survival (1).

CDC's National HIV Behavioral Surveillance (NHBS) monitors behaviors among populations at risk for acquiring or transmitting HIV infection. Recent NHBS data indicate that persons at risk for HIV infection who had ever received testing for HIV are testing at shorter intervals than in the past (2). The average interval in months between two successive HIV tests decreased from 21.1 in 2010 to 19.9 in 2013 among heterosexuals at increased risk for HIV, from 10.5 in 2009 to 7.7 in 2014 among men who have sex with men, and from 14.4 in 2009 to 11.5 in 2015 among persons who inject drugs.

Additional information on National HIV Testing Day is available at https://www.cdc.gov/features/HIVtesting. Basic testing information for consumers is available at https://www.cdc.gov/hiv/basics/testing.html. Additional information on HIV testing for health professionals is available at https://www.cdc.gov/hiv/testing. CDC's guidelines for HIV testing of serum and plasma specimens is available at https://www.cdc.gov/hiv/guidelines/ testing.html.

\section{References}

1. CDC. HIV diagnosis, care, and treatment among persons living with HIV-United States, 2011. MMWR Morb Mortal Wkly Rep 2014;63:1113-7.

2. An Q, Song R, Finlayson TJ, Wejnert C, Paz-Bailey G; NHBS Study Group. Estimated HIV inter-test interval among people at high risk for HIV infection in the US. Am J Prev Med 2017. http://www. sciencedirect.com/science/article/pii/S0749379717301435

\section{HIV Testing, Linkage to HIV Medical Care, and Interviews for Partner Services Among Youths - 61 Health Department Jurisdictions, United States, Puerto Rico, and the U.S. Virgin Islands, 2015}

\author{
Renee Stein, $\mathrm{PhD}^{1}$; Wei Song, $\mathrm{PhD}^{1}$; Mariette Marano, $\mathrm{MPH}^{1}$; \\ Heta Patel, $\mathrm{MPH}^{1}$; Shubha Rao, $\mathrm{MPH}^{1}$; Elana Morris, $\mathrm{MPH}^{1}$
}

Identifying persons living with human immunodeficiency virus (HIV) who are unaware of their infection, linking them to HIV medical care, and reducing health disparities are important national goals (1). Of the 8,841 teens and young adults aged 13-24 years (collectively referred to as youths in this report) who received a diagnosis of HIV in 2014, 70\% were young men who have sex with men (MSM) (2). In the same year, an estimated $52 \%$ of young MSM living with HIV were unaware of their infection compared with $15 \%$ among all persons living with HIV (3). An average of $22 \%$ of high school students who have had sexual intercourse and $33 \%$ of young adults (persons aged 18-24 years) reported ever receiving an HIV test (4). CDC recommends screening all persons aged 13-64 years, with annual rescreening for persons at high risk

\section{INSIDE \\ 636 Evaluation of Placental and Fetal Tissue Specimens for Zika Virus Infection - 50 States and District of Columbia, January-December, 2016 \\ 644 Screening for Syphilis and Other Sexually Transmitted Infections in Pregnant Women - Guam, 2014 \\ 649 Progress Toward Containment of Poliovirus Type 2 - Worldwide, 2017 \\ 654 QuickStats}

Continuing Education examination available at https://www.cdc.gov/mmwr/cme/conted_info.html\#weekly.

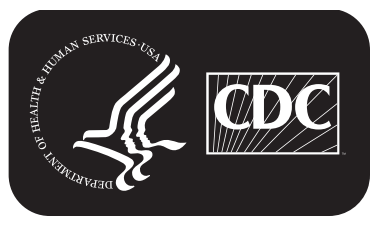


for HIV infection (5). Analysis of CDC-funded program data for youths submitted by 61 health departments in 2015 revealed that young MSM, who accounted for $83 \%$ of new diagnoses among all youths in non-health care facilities, received $28 \%$ of HIV tests. ${ }^{*}$ The 2020 national goal is to link at least $85 \%$ of HIV-positive persons to HIV medical care within 30 days of diagnosis. In this analysis, $66 \%$ of youths who received positive test results for HIV infection were linked to care within 90 days of diagnosis. Increasing the number of youths at risk for HIV infection who are tested for HIV on a regular basis and ensuring that youths who receive positive test results for HIV are rapidly linked to and retained in appropriate medical care, including early initiation of antiretroviral therapy, are essential steps for reducing HIV infection in this vulnerable population.

In 2015, CDC funded 61 state and local health departments and 123 community-based organizations $(\mathrm{CBOs})^{\dagger}$ to provide HIV testing and related services in the United States, Puerto Rico, and the U.S. Virgin Islands. Health departments submitted deidentified program data about services provided by both

\footnotetext{
* Non-health care facilities are settings where HIV testing is performed using a targeted testing strategy rather than a routine screening strategy. Examples of non-health care facilities include HIV testing sites and community settings. $\dagger$ CDC-funded partners include health departments in 50 states, the District of Columbia, Puerto Rico, the U.S. Virgin Islands, and eight directly funded city/ county health departments (Baltimore, Maryland; Chicago, Illinois; Fulton County, Georgia; Houston, Texas; Los Angeles County, California; New York City, New York; Philadelphia, Pennsylvania; and San Francisco, California) and 123 directly funded community-based organizations. Community-based organizations report their National HIV Prevention Program Monitoring and Evaluation HIV testing data to their jurisdiction's health department who then submit them to CDC.
}

health departments and CBOs, through a secure, online, CDCsupported system. Data from 2015 analyzed for this report include CDC-funded HIV tests, ${ }^{\S}$ new positive diagnoses, linkage of persons with newly or previously identified HIV to medical care within 90 days of diagnosis, 9 and interviews for partner services** among youths. Data were stratified by the following demographic characteristics: age group, race/ethnicity, gender, test setting, census region, and health department jurisdiction's HIV prevalence. ${ }^{\dagger \dagger}$

\footnotetext{
$\S$ An HIV test is defined as the performance of one or more HIV tests to determine a person's HIV infection status. A person might be tested once (e.g., one rapid test or one conventional test) or multiple times (e.g., one rapid test followed by one conventional test to confirm a preliminary HIV-positive test result).

I Linkage to HIV medical care within 90 days of diagnosis means confirmation that the person attended their first HIV medical care appointment within 90 days of their HIV test date.

** "Partner services" is a process through which HIV infected persons are interviewed to elicit information about their partners, who can then be confidentially notified of their possible exposure or potential risk and offered services that can protect the health of partners and prevent HIV transmission to others.

$\dagger \dagger$ Jurisdictions are grouped by HIV prevalence as determined by the number of persons living with diagnosed HIV infection in 2013: high: $\geq 20,000$; medium: 4,000-19,999; medium-low/low: $\leq 3,999$. High prevalence jurisdictions include the following: California, Los Angeles, San Francisco; Florida; Georgia, Fulton County (Atlanta); Chicago, Illinois; Maryland, Baltimore; New Jersey; New York, New York City; North Carolina; Pennsylvania, Philadelphia; Texas, Houston; and Virginia. Medium prevalence jurisdictions include Alabama; Arizona; Arkansas; Colorado; Connecticut; District of Columbia; Indiana; Kentucky; Louisiana; Massachusetts; Michigan; Minnesota; Mississippi; Missouri; Nevada; Ohio; Oklahoma; Oregon; Puerto Rico; South Carolina; Tennessee; Washington; and Wisconsin. Medium-low/low prevalence jurisdictions include Alaska; Delaware; Hawaii; Idaho; Iowa; Kansas; Maine; Montana; Nebraska; New Hampshire; New Mexico; Rhode Island; South Dakota; U.S. Virgin Islands; Utah; Vermont; West Virginia; and Wyoming.
}

The MMWR series of publications is published by the Center for Surveillance, Epidemiology, and Laboratory Services, Centers for Disease Control and Prevention (CDC), U.S. Department of Health and Human Services, Atlanta, GA 30329-4027.

Suggested citation: [Author names; first three, then et al., if more than six.] [Report title]. MMWR Morb Mortal Wkly Rep 2017;66:[inclusive page numbers]

\section{Centers for Disease Control and Prevention}

Anne Schuchat, MD, Acting Director

Patricia M. Griffin, MD, Acting Associate Director for Science

Joanne Cono, MD, ScM, Director, Office of Science Quality

Chesley L. Richards, MD, MPH, Deputy Director for Public Health Scientific Services

Michael F. Iademarco, MD, MPH, Director, Center for Surveillance, Epidemiology, and Laboratory Services

\section{MMWR Editorial and Production Staff (Weekly)}

Sonja A. Rasmussen, MD, MS, Editor-in-Chief

Charlotte K. Kent, $\mathrm{PhD}$, MPH, Executive Editor Jacqueline Gindler, MD, Editor

Teresa F. Rutledge, Managing Editor

Douglas W. Weatherwax, Lead Technical Writer-Editor

Soumya Dunworth, PhD, Kristy Gerdes, MPH, Teresa M. Hood, MS, Technical Writer-Editors

\section{MMWR Editorial Board}

Timothy F. Jones, MD, Chairman

Matthew L. Boulton, MD, MPH

Virginia A. Caine, MD

Katherine Lyon Daniel, PhD

Jonathan E. Fielding, MD, MPH, MBA

David W. Fleming, MD

\author{
William E. Halperin, MD, DrPH, MPH \\ King K. Holmes, MD, PhD \\ Robin Ikeda, MD, MPH \\ Rima F. Khabbaz, MD \\ Phyllis Meadows, $\mathrm{PhD}, \mathrm{MSN}, \mathrm{RN}$ \\ Jewel Mullen, MD, MPH, MPA
}

Martha F. Boyd, Lead Visual Information Specialist

Maureen A. Leahy, Julia C. Martinroe, Stephen R. Spriggs, Tong Yang, Visual Information Specialists

Quang M. Doan, MBA, Phyllis H. King,

Terraye M. Starr, Moua Yang,

Information Technology Specialists
Jeff Niederdeppe, $\mathrm{PhD}$

Patricia Quinlisk, MD, MPH

Patrick L. Remington, MD, MPH

Carlos Roig, MS, MA

William L. Roper, MD, MPH

William Schaffner, MD 
Tests performed in non-health care facilities were stratified by target population. ${ }^{\$ \$}$ Multivariate log-binomial regression was used to assess the association between demographic characteristics and newly diagnosed HIV infections, linkage to HIV medical care, and interviews for partner services. To analyze linkage to HIV medical care among previously diagnosed HIV-positive youths, modified Poisson regression analysis was used, and the association between the target population and newly diagnosed HIV infections in non-health care facilities was assessed using univariate log-binomial regression.

Among 3,026,074 CDC-funded tests provided in 2015, a total of $838,342(28 \%)$ were provided to youths. Among youths, the highest percentages of tests were provided to persons who were aged $20-24$ years (74\%), female (55\%), and black (50\%) and were provided in health care facilities (76\%), in the South (58\%), and in medium and high prevalence jurisdictions (97\%). The highest percentages of tests performed in non-health care facilities were provided to young heterosexual females $(36 \%)$, young heterosexual males $(30 \%)$, and young MSM (28\%) (Table 1). Findings indicated that compared with youths aged 20-24 years, those aged 13-19 years were less likely to have newly diagnosed infection (adjusted prevalence ratio $[\mathrm{aPR}]=0.51)$. White youths $(0.22 \%$; $\mathrm{aPR}=0.45)$, Hispanic/Latino youths $(0.39 \%$; $\mathrm{aPR}=0.70)$, and youths of other racial/ethnic groups $9.32 \%$; aPR $=0.50)$ were less likely to have newly diagnosed infection than were black youths $(0.44 \%)$. Tests in health care facilities were less likely to yield new diagnoses than tests performed in non-health care facilities $(\mathrm{aPR}=0.60)$ (Table 1$)$. Compared with tests performed in the South, tests performed in the Northeast were less likely to yield new diagnoses $(\mathrm{aPR}=0.73)$, whereas tests performed in the West were more likely to yield new diagnoses $(\mathrm{aPR}=1.20)$. Tests performed in medium and medium-low/low prevalence jurisdictions were less likely to yield new diagnoses $(\mathrm{aPR}=0.75$ and $\mathrm{aPR}=0.62$, respectively) than tests performed in high prevalence jurisdictions (Table 1). Findings in non-health care facilities indicated that compared with young MSM, transgender youths, youths who inject drugs, young heterosexual males, and young heterosexual females were all less likely to receive a new diagnosis of HIV infection $(\mathrm{aPRs}=0.64,0.19$, 0.08 , and 0.05 , respectively) (Table 1 ).

Among 2,973 youths who received a new diagnosis of HIV infection, 1,955 (66\%) were linked to HIV medical care within 90 days of diagnosis, and 1,871 (63\%) were interviewed for partner services (Table 2). Compared with the South (64\%), the prevalence of being linked to HIV medical care within 90 days of

\footnotetext{
$\$ \$$ Target population data are available only for tests performed in non-health care facilities and not for tests performed in health care facilities.

Is Other races/ethnicities include Asian, American Indian or Alaska Native, and Native Hawaiian or Pacific Islander.
}

diagnosis was lower in the Midwest $(49 \%$; $\mathrm{aPR}=0.81)$ but higher in the Northeast $(78 \%$; $\mathrm{aPR}=1.18)$, West $(77 \%$; $\mathrm{aPR}=1.16)$, and U.S. dependent areas*** $(86 \% ; \mathrm{aPR}=1.50)$ (Table 2). The prevalence of being interviewed for partner services in the South was $62 \%$; compared with the South, this prevalence was higher in the West $(70 \%$; aPR $=1.09)$ and the U.S. dependent areas $(84 \%$; aPR $=1.34)($ Table 2$)$.

Among 4,884 HIV infections identified among youths, 1,911 (39\%) had been previously diagnosed, and 1,749 (92\%) of these youths with previously diagnosed infection were not in HIV medical care at the time of testing (Table 1) (Table 3). Among the 1,749 youths with previously diagnosed infection who were not in HIV medical care, $66 \%$ were linked to care within 90 days of diagnosis. Compared with the South, where the prevalence of being linked to care was $61 \%$, the prevalence was higher in the Northeast $(77 \%$; aPR $=1.30)$, Midwest $(74 \%$; $\mathrm{aPR}=1.21)$, and the West $(83 \%$; $\mathrm{aPR}=1.33)$.

\section{Discussion}

Among youths living with HIV infection, testing and partner services are important strategies for diagnosis and prompt linkage to medical care so they can achieve viral suppression and reduce their risk for transmission to others. A national surveillance study determined that $92 \%$ of new infections in 2009 were acquired from persons with HIV who were not in medical care, underscoring the importance of early diagnosis and ongoing care and treatment (G). Given that approximately half of young MSM living with HIV are unaware of their status, and that the testing rates among youths are relatively low, improving the number of youths who are tested is of high importance $(3,4)$. Including HIV testing as part of routine medical care for youths is key to increasing early diagnosis, and a health care provider's testing recommendation is the most important predictor of testing among adolescents at risk for HIV infection (7). It is especially important to test young MSM because they are most disproportionately affected by HIV. In this analysis, young MSM, who accounted for $83 \%$ of new HIV infection diagnoses among all youths in nonhealth care facilities, received $28 \%$ of the tests. Expanding testing in places where youths might interact with the health care system, and providing youth- and lesbian/gay/bisexual/ transgender-friendly services, might increase testing among youths, especially young MSM (8).

By 2020, national goals call for linking $85 \%$ of persons who received a new diagnosis of HIV infection to medical care within 30 days of diagnosis (1). Findings from this report indicate that approximately two thirds (66\%) of youths who received a diagnosis of HIV infection in 2015 through

*** For this report, U.S. dependent areas include only Puerto Rico and the U.S. Virgin Islands. 
TABLE 1. HIV tests and newly diagnosed HIV infections among youths, ${ }^{*}$ by selected characteristics - United States, Puerto Rico, and the U.S. Virgin Islands, 2015

\begin{tabular}{|c|c|c|c|c|c|c|c|c|}
\hline \multirow[b]{2}{*}{ Characteristic } & \multirow[b]{2}{*}{$\begin{array}{l}\text { No. all } \\
\text { HIV tests }\end{array}$} & \multicolumn{2}{|c|}{ HIV tests $^{\dagger}$ among youths } & \multirow{2}{*}{$\begin{array}{l}\text { No. all newly } \\
\text { diagnosed HIV } \\
\text { infections }\end{array}$} & \multicolumn{4}{|c|}{ Newly diagnosed HIV infections ${ }^{\S}$ among youths } \\
\hline & & No. (\%) & $\begin{array}{l}\% \text { of } \\
\text { subgroup }\end{array}$ & & No. (\%) & $\begin{array}{l}\text { \% of } \\
\text { subgroup }\end{array}$ & $\begin{array}{c}\% \\
\text { Positive }\end{array}$ & aPR $(95 \% \mathrm{Cl})$ \\
\hline \multicolumn{9}{|l|}{ Age group (yrs) } \\
\hline $13-19$ & 221,338 & - & 26.4 & 415 & - & 14.0 & 0.19 & $0.51(0.45-0.56)^{9}$ \\
\hline $20-24$ & 617,004 & - & 73.6 & 2,558 & - & 86.0 & 0.41 & Reference \\
\hline \multicolumn{9}{|l|}{ Gender** } \\
\hline Male & $1,535,214$ & $374,757(24.4)$ & 45.0 & 10,531 & $2,661(25.3)$ & 89.6 & 0.71 & Reference \\
\hline Female & $1,457,341$ & $453,198(31.1)$ & 54.5 & 1,801 & $256(14.2)$ & 8.6 & 0.06 & $0.09(0.08-0.10)^{\text {ศ }}$ \\
\hline Transgender & 13,097 & $4,299(32.8)$ & 0.5 & 187 & $52(27.8)$ & 1.8 & 1.21 & $1.66(1.26-2.18)^{9}$ \\
\hline \multicolumn{9}{|l|}{ Race/Ethnicity** } \\
\hline White & 785,623 & $201,135(25.6)$ & 25.6 & 2,657 & $440(16.6)$ & 15.1 & 0.22 & $0.45(0.41-0.50)^{9}$ \\
\hline Black or African American & 1,304,956 & $396,327(30.4)$ & 50.4 & 5,843 & $1,727(29.6)$ & 59.3 & 0.44 & Reference \\
\hline Hispanic or Latino & 647,773 & $159,865(24.7)$ & 20.3 & 3,253 & $626(19.2)$ & 21.5 & 0.39 & $0.70(0.63-0.77)^{9}$ \\
\hline Other ${ }^{\dagger \dagger}$ & 87,176 & $21,081(24.2)$ & 2.7 & 335 & $67(20.0)$ & 2.3 & 0.32 & $0.50(0.39-0.64)^{9}$ \\
\hline Multiple races & 21,015 & $8,510(40.5)$ & 1.1 & 124 & $51(41.1)$ & 1.8 & 0.60 & $0.99(0.75-1.31)$ \\
\hline \multicolumn{9}{|l|}{ Test setting** } \\
\hline Health care facility & $2,313,742$ & $633,088(27.4)$ & 75.8 & 7,623 & $1,665(21.8)$ & 56.3 & 0.26 & $0.60(0.56-0.65)^{9}$ \\
\hline Non-health care facility & 703,890 & $202,181(28.7)$ & 24.2 & 4,860 & $1292(26.6)$ & 43.7 & 0.64 & Reference \\
\hline \multicolumn{9}{|l|}{ U.S. Census region } \\
\hline Northeast & 480,665 & $125,699(26.2)$ & 15.0 & 1,888 & $373(19.7)$ & 12.6 & 0.30 & $0.73(0.65-82)^{9}$ \\
\hline Midwest & 419,516 & $126,792(30.2)$ & 15.1 & 1,549 & $439(28.3)$ & 14.8 & 0.35 & $1.07(0.96-1.20)$ \\
\hline South & $1,689,548$ & $488,561(29.0)$ & 58.3 & 6,296 & $1687(26.8)$ & 56.7 & 0.35 & Reference \\
\hline West & 391,353 & $84,675(21.7)$ & 10.1 & 2,564 & 431 (16.8) & 14.5 & 0.51 & $1.20(1.07-1.35)^{\S \S}$ \\
\hline U.S. dependent areas & 44,992 & $12,615(28.0)$ & 1.5 & 250 & $43(17.2)$ & 1.5 & 0.34 & $1.31(0.95-1.80)$ \\
\hline \multicolumn{9}{|l|}{ HIV prevalence } \\
\hline High & $1,784,092$ & $460,162(25.8)$ & 54.9 & 8,421 & $1,923(22.8)$ & 64.7 & 0.42 & Reference \\
\hline Medium & $1,150,815$ & $350,075(30.4)$ & 41.8 & 3,830 & $981(25.6)$ & 33.0 & 0.28 & $0.75(0.69-0.82)^{\curvearrowleft}$ \\
\hline Medium-low/Low & 91,167 & $28105(30.8)$ & 3.4 & 296 & $69(23.3)$ & 2.3 & 0.25 & $0.62(0.49-0.80)^{9}$ \\
\hline Overall total & $3,026,074$ & $838,342(27.7)$ & 100.0 & 12,547 & $2,973(23.7)$ & 100.0 & 0.35 & - \\
\hline \multicolumn{9}{|c|}{ Target population (non-health care facilities only) } \\
\hline Men who have sex with men & 153,842 & $42,184(27.4)$ & 28.2 & 2,891 & $883(30.5)$ & 82.8 & 2.09 & Reference \\
\hline Transgender persons & 5,445 & $1,860(34.2)$ & 1.2 & 98 & $25(25.5)$ & 2.3 & 1.34 & $0.64(0.43-0.9 .5)^{* * *}$ \\
\hline Persons who inject drugs & 37,212 & $6,425(17.3)$ & 4.3 & 254 & $26(10.2)$ & 2.4 & 0.40 & $0.19(0.13-0.29)^{\pi}$ \\
\hline Heterosexual males & 159,948 & $44,641(27.9)$ & 29.9 & 464 & $75(16.2)$ & 7.0 & 0.17 & $0.08(0.06-0.10)^{9}$ \\
\hline Heterosexual females & 154,598 & $54,323(35.1)$ & 36.4 & 312 & $57(18.3)$ & 5.3 & 0.10 & $0.05(0.04-0.07)^{\natural}$ \\
\hline Total in non-health care facilities & 703,890 & $202,181(28.7)$ & 100.0 & 4,860 & $1,292(26.6)$ & 100.0 & 0.64 & - \\
\hline \multicolumn{9}{|c|}{$\begin{array}{l}\text { †alid HIV tests were defined as tests for which a test result (i.e., positive or negative) was known. Analyses excluded discordant and indeterminate results. } \\
\S \text { Included are persons who tested HIV-positive and did not report a previous positive test result, calculated using HIV surveillance verification (if available) or a } \\
\text { person's self-reported previous HIV status. } \\
\text { ๓ Significant at } p<0.001 \text {. }\end{array}$} \\
\hline \multicolumn{9}{|c|}{$\begin{array}{l}\text { ** Missing/invalid data were excluded. In the category "HIV tests among youths," } 6,088(0.73 \%) \text { records were excluded from gender, } 51,424(6.13 \%) \text { from race/ethnicity, } \\
\text { and 3,073 (0.37\%) from test setting. In the category"newly diagnosed HIV infection among youths," four (0.13\%) were excluded from gender, } 62(2.09 \%) \text { from race/ } \\
\text { ethnicity, and } 16(0.54 \%) \text { from test setting. }\end{array}$} \\
\hline \multicolumn{9}{|c|}{$\begin{array}{l}\text { t+ Includes Asian, American Indian or Alaska Native, and Native Hawaiian or Pacific Islander. } \\
\S \S \text { Significant at } p<0.01 .\end{array}$} \\
\hline \multicolumn{9}{|c|}{$\begin{array}{l}\text { १ी Target population data are available only for tests performed in non-health care facilities and not for tests performed in health care facilities. Therefore, these data } \\
\text { come from non-health care facilities only. Records that specified other target population and those with missing/invalid data were excluded. In the category"HIV } \\
\text { tests among youths," 33,703 (16.67\%) records that specified other target population and 19,045 (9.42\%) records with missing/invalid data were excluded. In the } \\
\text { category "newly diagnosed HIV infection among youths," } 208(16.10 \%) \text { records that specified other target population and } 18 \text { (1.39\%) records with missing/invalid } \\
\text { data were excluded. }\end{array}$} \\
\hline
\end{tabular}


TABLE 2. Linkage to HIV medical care and interviews for partner services among newly diagnosed HIV-positive youths, ${ }^{*}$ by selected characteristics United States, Puerto Rico, and the U.S. Virgin Islands, 2015

\begin{tabular}{|c|c|c|c|c|c|c|c|}
\hline \multirow[b]{2}{*}{ Characteristic } & \multirow{2}{*}{$\begin{array}{c}\text { No. newly } \\
\text { diagnosed HIV } \\
\text { infections, }^{\dagger} \\
\text { (\% of total) }\end{array}$} & \multicolumn{3}{|c|}{ Linked to HIV medical care within 90 days of diagnosis $\$$} & \multicolumn{3}{|c|}{ Interviewed for partner services? } \\
\hline & & No. (\% of subgroup) & aPR $(95 \% \mathrm{Cl})$ & $\begin{array}{c}\text { No. missing } \\
\text { linkage info. (\%) }\end{array}$ & No $(\%)$ & aPR $(95 \% \mathrm{Cl})$ & $\begin{array}{c}\text { No. missing } \\
\text { linkage info. (\%) }\end{array}$ \\
\hline \multicolumn{8}{|l|}{ Age group (yrs) } \\
\hline $13-19$ & $415(14.0)$ & $263(63.4)$ & $0.95(0.88-1.03)$ & $121(29.2)$ & $258(62.2)$ & $0.98(0.90-1.06)$ & $88(21.2)$ \\
\hline $20-24$ & $2,558(86.0)$ & $1,692(66.1)$ & Reference & $582(22.8)$ & $1,613(63.1)$ & Reference & $475(18.6)$ \\
\hline \multicolumn{8}{|l|}{ Gender** } \\
\hline Male & 2,661 (86.9) & $1,758(66.1)$ & Reference & $624(23.5)$ & 1,693 (63.6) & Reference & $500(18.8)$ \\
\hline Female & $256(8.6)$ & $163(63.7)$ & $1.00(0.91-1.10)$ & $68(26.6)$ & $147(57.4)$ & $0.92(0.83-1.03)$ & $47(18.4)$ \\
\hline Transgender & $52(1.8)$ & $31(59.6)$ & $0.89(0.72-1.10)$ & $11(21.2)$ & $28(53.9)$ & $0.86(0.67-1.11)$ & $16(30.8)$ \\
\hline \multicolumn{8}{|l|}{ Race/Ethnicity** } \\
\hline White & $440(15.1)$ & $302(68.6)$ & $1.08(0.99-1.16)$ & $93(21.1)$ & $275(62.5)$ & $0.97(0.88-1.05)$ & $74(16.8)$ \\
\hline $\begin{array}{c}\text { Black or African } \\
\text { American }\end{array}$ & $1,727(59.3)$ & $1,085(62.8)$ & Reference & $437(25.3)$ & $1,074(62.2)$ & Reference & $355(20.6)$ \\
\hline Hispanic or Latino & $626(21.5)$ & $460(73.5)$ & 1.04 (0.97-1.10) & $127(20.3)$ & $424(67.7)$ & $1.00(0.94-1.08)$ & $89(14.2)$ \\
\hline Othertt & $67(2.3)$ & $52(77.6)$ & $1.11(0.98-1.26)$ & $9(13.4)$ & 40 (59.7) & $0.89(0.73-1.08)$ & $13(19.4)$ \\
\hline Multiple races & $51(1.8)$ & $32(62.7)$ & $0.96(0.78-1.18)$ & $15(29.4)$ & $29(56.9)$ & $0.88(0.70-1.11)$ & $12(23.5)$ \\
\hline \multicolumn{8}{|l|}{ Test setting** } \\
\hline Health care facility & $1,665(56.3)$ & $1,093(65.6)$ & $1.00(0.95-1.05)$ & $396(23.8)$ & $1,052(63.2)$ & $1.01(0.95-1.07)$ & $302(18.1)$ \\
\hline $\begin{array}{l}\text { Non-health care } \\
\text { facility }\end{array}$ & $1,292(43.7)$ & $853(66.0)$ & Reference & $304(23.5)$ & 807 (62.5) & Reference & $260(20.1)$ \\
\hline \multicolumn{8}{|l|}{ U.S. Census region } \\
\hline Northeast & $373(12.5)$ & $292(78.3)$ & $1.18(1.11-1.27)^{\S \S}$ & $49(13.1)$ & $245(65.7)$ & 1.05 (0.97-1.15) & $81(21.7)$ \\
\hline Midwest & 439 (14.8) & $216(49.2)$ & $0.81(0.73-0.90)^{\S \S}$ & $157(35.8)$ & $240(54.7)$ & $0.85(0.77-0.94)$ & $68(15.5)$ \\
\hline South & 1,687 (56.7) & $1,077(63.8)$ & Reference & $423(25.1)$ & $1,049(62.2)$ & Reference & $383(22.7)$ \\
\hline West & 431 14.5) & $333(77.3)$ & $1.16(1.09-1.25)^{\S \S}$ & $681(5.8)$ & $301(69.8)$ & 1.09 (1.01-1.18) & $26(6.0)$ \\
\hline $\begin{array}{l}\text { U.S. dependent } \\
\text { areas }\end{array}$ & $43(1.4)$ & $37(86.0)$ & $1.50(1.29-1.74)^{\S \S}$ & 6 14.0) & $36(83.7)$ & $1.341 .14-1.58)^{\S \S}$ & $5(11.6)$ \\
\hline \multicolumn{8}{|l|}{ HIV prevalence } \\
\hline High & $1,923(64.7)$ & $1,48(70.1)$ & Reference & 388 20.2) & $1,217(63.3)$ & Reference & $353(18.4)$ \\
\hline Medium & $981(33.0)$ & $545(55.6)$ & $0.83(0.78-0.89)^{\S \S}$ & $31131.7)$ & $590(60.1)$ & $0.990 .92-1.06)$ & $208(21.2)$ \\
\hline Medium-low/Low & $69(2.3)$ & $62(89.9)$ & $1.30(1.18-1.44)^{\S \S}$ & $45.8)$ & $64(92.8)$ & $1.641 .49-1.81)^{\S \S}$ & $2(2.9)$ \\
\hline Overall total & 2,973 & $1,955(65.8)$ & - & $70323.7)$ & $1,871(62.9)$ & - & 563 (18.9) \\
\hline
\end{tabular}

Abbreviations: aPR = adjusted prevalence ratio; HIV = human immunodeficiency virus.

* Youths are defined as teens and young adults aged 13-24 years.

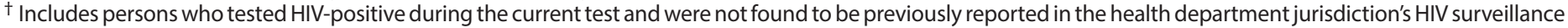
system or self-reported not having a previous HIV-positive test result if surveillance system verification was not available.

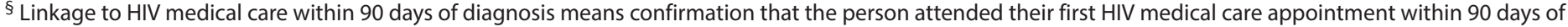
their diagnosis.

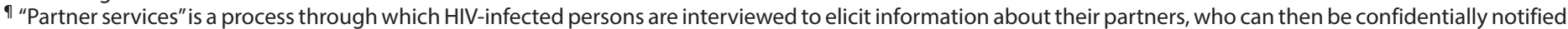
of their possible exposure or potential risk and offered services that can protect the health of partners and prevent HIV transmission to others.

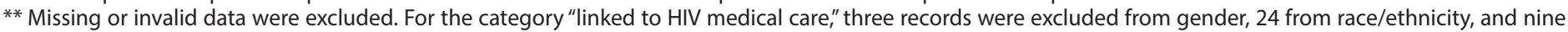

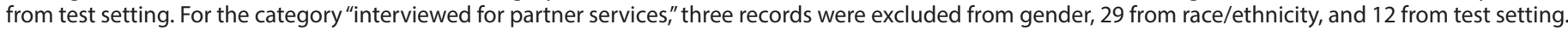

†† Includes Asian, American Indian or Alaska Native, and Native Hawaiian or Pacific Islander.

$\S \S$ Significant at $p<0.001$.

ๆๆ Significant at $p<0.05$.

CDC-funded HIV testing programs were linked to care within 90 days of diagnosis. Among youths who received a new HIV infection diagnosis, $63 \%$ were interviewed for partner services. The greatest need for improvement appears to be in the South and the Midwest, where rates of linkage and interviews for partner services were relatively low. These low rates are particularly concerning for the South because in 2015, approximately $52 \%$ of new diagnoses of HIV infection in the United States occurred in the region (9).

In this analysis, 39\% of youths who received an HIV-positive test result had already received a diagnosis of HIV infection in the past, and $92 \%$ of those persons were not in HIV medical care at the time of the test. Youths who have previously received a diagnosis of HIV infection and are willing to receive a test present an important HIV treatment opportunity. Youths might face multiple barriers to treatment, such as consent and confidentiality, inability to pay for services, housing instability, stigma, lack of transportation, and mental health and substance use, which might need to be addressed for successful linkage and retention to care $(8)$.

The findings in this report are subject to at least three limitations. First, findings describe CDC-funded HIV tests only and are not generalizable to all youths in the United States. Second, linkage data include records with missing or invalid data in 
TABLE 3. Linkage to HIV medical care among previously diagnosed HIV-positive youths,* by selected characteristics, United States, Puerto Rico, and the U.S. Virgin Islands, 2015

\begin{tabular}{|c|c|c|c|c|c|}
\hline \multirow[b]{2}{*}{ Characteristic } & \multirow{2}{*}{$\begin{array}{l}\text { No. previously } \\
\text { diagnosed HIV } \\
\text { infections }^{\dagger}\end{array}$} & \multirow{2}{*}{$\begin{array}{c}\text { No. not in HIV medical } \\
\text { care at time of current } \\
\text { HIV test }(\%)\end{array}$} & \multicolumn{3}{|c|}{$\begin{array}{l}\text { Previously diagnosed HIV-positive youths not in HIV medical care at time of this test } \\
\text { who were then linked to } \text { care }^{\S}\end{array}$} \\
\hline & & & No. (\%) & $\operatorname{aPR}(95 \% \mathrm{Cl})$ & No. missing linkage info (\%) \\
\hline \multicolumn{6}{|l|}{ Age group (yrs) } \\
\hline $13-19$ & 216 & $197(91.2)$ & $134(68.0)$ & $1.02(0.93-1.13)$ & $33(16.8)$ \\
\hline $20-24$ & 1,695 & $1,552(91.6)$ & $1,023(65.9)$ & Reference & $350(22.6)$ \\
\hline \multicolumn{6}{|l|}{ Gender" } \\
\hline Male & 1,615 & $1,474(91.3)$ & $986(66.9)$ & Reference & $311(21.1)$ \\
\hline Female & 256 & $239(93.4)$ & $149(62.3)$ & $0.94(0.85-1.05)$ & $62(25.9)$ \\
\hline Transgender & 31 & $27(87.1)$ & $19(70.3)$ & $1.02(0.80-1.30)$ & $7(25.9)$ \\
\hline \multicolumn{6}{|l|}{ Race/Ethnicityף } \\
\hline White & 221 & $213(96.4)$ & $156(73.2)$ & $1.09(0.99-1.20)$ & $40(18.8)$ \\
\hline Black or African American & 1,328 & $1,192(89.8)$ & $775(65.0)$ & Reference & $268(22.5)$ \\
\hline Hispanic or Latino & 243 & $232(95.5)$ & $167(72.0)$ & $1.06(0.96-1.17)$ & $43(18.5)$ \\
\hline Other** & 26 & $26(100.0)$ & $20(76.9)$ & $1.07(0.85-1.33)$ & $3(11.5)$ \\
\hline Multiple races & 15 & $14(93.3)$ & $7(50.0)$ & $0.72(0.43-1.20)$ & $5(35.7)$ \\
\hline \multicolumn{6}{|l|}{ Test setting" } \\
\hline Health care facility & 1,433 & $1,304(91.0)$ & $868(66.6)$ & $1.01(0.93-1.10)$ & $280(21.5)$ \\
\hline Non-health care facility & 470 & $438(93.2)$ & $287(65.5)$ & Reference & $100(22.8)$ \\
\hline \multicolumn{6}{|l|}{ U.S. Census region } \\
\hline Northeast & 129 & $112(86.8)$ & $86(76.8)$ & $1.30(1.16-1.46)^{\dagger \dagger}$ & $19(17.0)$ \\
\hline Midwest & 325 & $276(84.9)$ & $203(73.6)$ & $1.21(1.11-1.33)^{\dagger \dagger}$ & $42(15.2)$ \\
\hline South & 1,294 & $1,210(93.5)$ & $742(61.3)$ & Reference & $306(25.3)$ \\
\hline West & 156 & $144(92.3)$ & $120(83.3)$ & $1.33(1.20-1.47)^{\dagger \dagger}$ & $16(11.1)$ \\
\hline U.S. dependent areas & 7 & $7(100.0)$ & $6(85.7)$ & $1.29(0.93-1.78)$ & $0(0.0)$ \\
\hline \multicolumn{6}{|l|}{ HIV prevalence } \\
\hline High & 1043 & $942(90.3)$ & $629(66.8)$ & Reference & $188(20.0)$ \\
\hline Medium & 854 & $797(93.3)$ & $521(65.4)$ & $1.07(1.00-1.15)$ & $193(24.2)$ \\
\hline Medium-low/Low & 14 & $10(71.4)$ & $7(70.0)$ & $0.95(0.66-1.38)$ & $2(20.0)$ \\
\hline Overall total & 1,911 & $1,749(91.5)$ & $1,157(66.2)$ & - & $383(21.9)$ \\
\hline
\end{tabular}

Abbreviations: $\mathrm{aPR}=$ adjusted prevalence ratio; $\mathrm{HIV}=$ human immunodeficiency virus.

* Youths are defined as teens and young adults aged 13-24 years.

† Previously diagnosed HIV infections include those who tested HIV-positive during the current test and were found to be previously reported in the health department's HIV surveillance system or self-reported having a previous HIV-positive test result if the surveillance system verification is not available.

$\S$ Linkage to HIV medical care within 90 days of diagnosis means confirmation that the person attended their first HIV medical care appointment within 90 days of receiving their diagnosis.

" Missing or invalid data were excluded. In the category "previously diagnosed HIV infections," nine records were excluded from gender, 78 from race/ethnicity, and eight from test setting. In the category "linked to care," three records were excluded from gender, 32 from race/ethnicity, and two from test setting.

** Includes Asian, American Indian or Alaska Native, and Native Hawaiian or Pacific Islander.

t+ Significant at $\mathrm{p}<0.001$

the denominator, and therefore probably underestimate the percentage of persons linked to care. Finally, when surveillance data are unavailable to verify prior HIV status, the number of new positive results might be overestimated if clients inaccurately report a previous negative HIV status.

Increasing the number of HIV tests among youths at risk for HIV and increasing regular retesting among these youths is essential for reducing HIV infection in this vulnerable population. This could be accomplished through a combined strategy of routine HIV testing among youths, especially young men, in health care settings, and targeted testing in places where youths at risk for HIV infection congregate. CDC currently funds $120 \mathrm{CBOs}$ to provide targeted testing to the populations most at risk for HIV infection; 30 of these CBOs specifically serve young MSM and transgender persons of color (10). Additional measures are needed to encourage health care providers to include HIV testing as a routine part of health care for youths. Schools can also play an important role in facilitating access to HIV testing for school-aged youth. Toward this end, CDC works with 18 state education agencies and 17 local education agencies to connect youths to community-based services, including HIV testing. Increased measures are also needed to ensure that youths who receive positive test results for HIV are rapidly linked to and retained in appropriate medical care, including early initiation of antiretroviral therapy. 


\section{Summary}

What is already known about this topic?

In 2014, 70\% of teens and young adults aged 13-24 (youths) who received a diagnosis of HIV infection were young men who have sex with men (MSM), 52\% of whom were unaware of their infection. HIV testing rates are low among youths, with $22 \%$ of sexually active high school students and $33 \%$ of young adults aged 18-24 years reporting ever having received an HIV test.

What is added by this report?

Analysis of 2015 data on CDC-funded HIV tests and HIV prevention services from 61 health departments and 123 communitybased organizations indicated that young MSM, who accounted for $83 \%$ of new diagnoses of HIV infection among all youths in non-health care facilities, received $28 \%$ of the tests in these settings. The 2020 national goal is to link at least $85 \%$ of HIVpositive persons to HIV medical care within 30 days of diagnosis; in this analysis, $66 \%$ of youths whose test results were positive for HIV were linked to care within 90 days of diagnosis. HIV disproportionately affects youths in the South, where linkage rates were among the lowest in the United States.

What are the implications for public health practice?

Increasing HIV testing among youths at risk for HIV infection is essential for reducing infections in this vulnerable population. This can be accomplished through a combined strategy of routine HIV testing of youths, especially young men, in health care settings and targeted testing in places where youths at risk for HIV infection congregate. Schools can also play an important role in facilitating access to HIV testing for school-aged youths. Increased measures are needed to ensure that youths testing positive for HIV are rapidly linked to and retained in appropriate medical care, including early initiation of antiretroviral therapy.

\section{Acknowledgments}

Prevention Program Branch staff members, Sam Dooley, Sonia Singh, Division of HIV/AIDS Prevention, National Center for HIV/ AIDS, Viral Hepatitis, STD, and TB Prevention, CDC.

\section{Conflict of Interest}

No conflicts of interest were reported.

\footnotetext{
${ }^{1}$ Division of HIV/AIDS Prevention, National Center for HIV/AIDS, Viral Hepatitis, STD, and TB Prevention, CDC.

Corresponding author: Renee Stein, rstein1@cdc.gov, 404-639-3517.
}

\section{References}

1. Office of National AIDS Policy. National HIV/AIDS strategy for the United States: updated to 2020. Washington, DC: Office of National AIDS Policy; 2015. https://obamawhitehouse.archives.gov/sites/default/ files/docs/national_hiv_aids_strategy_update_2020.pdf

2. CDC. Diagnoses of HIV infection among adolescents and young adults in the United States and 6 dependent areas, 2010-2014. Atlanta, GA: US Department of Health and Human Services, CDC; 2016. https:// www.cdc.gov/hiv/pdf/library/reports/surveillance/cdc-hiv-surveillancesupplemental-report-vol-21-3.pdf

3. Singh S, Song R, Satcher Johnson A, McCray E, Hall I. HIV incidence, prevalence, and undiagnosed infections in men who have sex with men. Presented at the Conference on Retroviruses and Opportunistic Infections, Seattle, Washington; February 13-16, 2017. http://www. hivdent.org/_CROI2017/HIV\%20Incidence.pdf

4. Van Handel M, Kann L, Olsen EO, Dietz P. HIV testing among US high school students and young adults. Pediatrics 2016;137:e20152700. https://doi.org/10.1542/peds.2015-2700

5. Branson BM, Handsfield HH, Lampe MA, et al. Revised recommendations for HIV testing of adults, adolescents, and pregnant women in healthcare settings. MMWR Recomm Rep 2006;55(No. RR-14).

6. Skarbinski J, Rosenberg E, Paz-Bailey G, et al. Human immunodeficiency virus transmission at each step of the care continuum in the United States. JAMA Intern Med 2015;175:588-96. https://doi.org/10.1001/ jamainternmed.2014.8180

7. Murphy DA, Mitchell R, Vermund SH, Futterman D; HIV/AIDS Research Network. Factors associated with HIV testing among HIVpositive and HIV-negative high-risk adolescents: the REACH Study. Pediatrics 2002;110:e36. https://doi.org/10.1542/peds.110.3.e36

8. Zanoni BC, Mayer KH. The adolescent and young adult HIV cascade of care in the United States: exaggerated health disparities. AIDS Patient Care STDS 2014;28:128-35. https://doi.org/10.1089/apc.2013.0345

9. CDC. HIV surveillance report: diagnoses of HIV infection in the United States and dependent areas, 2015. Atlanta, GA: US Department of Health and Human Services, CDC; 2016. https://www.cdc.gov/hiv/ pdf/library/reports/surveillance/cdc-hiv-surveillance-report-2015vol-27.pdf

10. CDC. Funding announcement PS17-1704: comprehensive high-impact HIV prevention projects for young men of color who have sex with men and young transgender persons of color. Atlanta, GA: US Department of Health and Human Services, CDC; 2016. https://www.cdc.gov/hiv/ funding/announcements/ps17-1704/index.html 